\title{
PICALM/MLLT10 Fusion Protein
}

National Cancer Institute

\section{Source}

National Cancer Institute. PICALM/MLLT10 Fusion Protein. NCI Thesaurus. Code C99584.

A fusion protein encoded by the PICALM/MLLT 10 fusion gene. This protein is comprised of all but the last 4 amino acids of the phosphatidylinositol-binding clathrin assembly protein fused to the C-terminal leucine zipper domain of protein AF-10. 